\title{
Problemas populacionais e educacionais
}

\section{Eduardo Lleras *}

O programa de desenvolvimento da Amazônia tem sido postulado basicamente como um programa de colonização agrícola acompanhando a implantação da Transamazônica (Rebelo, 1973), paralelo a um desenvolvimento industrial-urbano promovido, entre outros fatores pela Zona Franca de Manaus.

Este desenvolvimento requer um grande influxo de pessoal de fora da região, tanto nas áreas rurais, quanto urbanas. Um prelúdio à migração mássiva à Amazônia ocorreu entre os anos de 1887 a 1900 quando coincidiu um ciclo de seca no nordeste com o auge da borracha. Nesses 18 anos, só o Acre, experimentou uma imigração de mais de 160.000 pessoas provenientes do nordeste (Goodland \& Irwin, 1975)! Com a abertura da Transamazônica e implantação das Agrovilas, Goodland \& Irwin (1975) estimaram uma imigração rural massiva da ordem de 1.000.000 de pessoas, das quais metade em projetos governamentais e metade por invasão clandestina. Estimaram também que $75 \%$ destes imigrantes seriam nordestinos.

Em termos gerais, o pessoal que migra para áreas de colonização, migra por causa de pressões econômicas e demográficas que geraimente atingem as classes mais pobres $e$ menos instruídas da população. Assim, a maior parte dos imigrantes na Amazônia estaria representada por pessoal sem instrução e sem maiores qualificações. Sendo este o caso, o bem intencionado programa governamental de ocupar grandes extensões vazias com colonos e assim melhorar as condições dos mesmos, nem sempre seria bem sucedido devido a falta de condições dos colonos para explorar adequadamente a região.

Também, como conseqüência da falta de preparação dos colonos e os insucessos dos mesmos nas áreas rurais, haveria uma migra- ção massiva em direção aos três ou quatro grandes centros urbanos da Amazônia, onde iriam aumentar mais os problemas sociais $\mathrm{e}$ índices de desemprego dos mesmos.

Para tentar elucidar a real situação populacional e educacional da Amazônia, assim como o impacto das imigrações massivas postuladas por Goodland \& Irwin (1975), foi feito um levantamento dos dados estimativos demográficos e culturais dos Estados do Amazonas Pará e Mato Grosso( (1). Em alguns aspectos. os três Estados apresentam características comuns, sendo que diferem consideravelmente em outros.

\section{SITUAÇĀO DEMOGRÁFICA}

A Amazônia legal tem, atualmente, $6 \mathrm{mi}$ Ihões aproximadamente de habitantes de acordo com as estimativas do IBGE.

Para a região Norte, estima-se que em $1975,50 \%$ da população era urbana e $50 \%$ era rural. Esta situação, porém, não é estável, e de fato existe uma forte tendência para um aumento excessivo da população urbana em detrimento da população rural.

$\mathrm{Na}$ figura 1 , pode observar-se a evolução esperada (em base a uma taxa de crescimento de $3,3 \%$ anual) das populações urbanas e rural assim como a evolução real entre os anos de 1950 e 1980 (estimada) para o Estado do Amazonas

Como pode observar-se, o crescimento da população rural não está acompanhando a taxa de crescimento global da população $(3,3 \%$ ao ano), sendo que, para 1980, estima-se um deficit de crescimento rural da ordem de 312.000 pessoas; ao contrário há um excesso de crescimeno urbano com relação a taxa global de crescimento que para 1980 está eștimada em 350.000 pessoas, a maioria, no caso do Amazonas, concentrada em Manaus.

(1) - Os levantamentos estatísticos foram baseados no Anuário Estatístico do Amazonas (1975), Anuário Estatístico do Pará (1977) e Anuário Estatístico de Mato Grosso (1975) e não serão citados repetidamente no texto. 




Fig. 1 - Evolução da população urbana e rural no Estado do Amazonas entre 1950 e 1960. DCR, deficit de crescimento rural; ECU, excesso de crescimento urbano. Os dados para as 4 classes (população urbana estimada em base a crescimento de $3,3 \%$ anual a partir de 1950; população urbana real; população rural estimada em base a crescimento de 3,3\% anual a partir de 1950 e população rural real] todas iniciam no zero do gráfico.

A população total do Estado calculada com base nos dados de 1950 e um crescimento de $3,3 \%$ ao ano seria para 1980 da ordem de 1.361 .000 habitantes; os dados reais baseados em censos e outros tipos de levantamento dão uma estimativa para 1980, de 1.399.000 aproximadamente.

Em termos gerais, no Estado do Amazonas, a população passou de ser $73 \%$ rural e $27 \%$ urbana em 1950 a ser $49 \%$ rural e $51 \%$ urbana em 1980 (estimado). Não há evidência nenhuma de uma imigração massiva nestes 30 anos, sendo que o incremento de 30.000 habitantes acima do esperado está dentro do padrão de erro da estimativa.

A situação, para o Estado do Pará é diferente quanto à evolução dos crescimentos populacionais urbano e rural. Em 1971, a população rural compreendia $52,5 \%$ da população total, sendo que em 1980, calcula-se em $50,8 \%$; O deficit rural para 1980 entre os dados reais e esperados é de somente 4.000 pessoas, havendo porém um excesso urbano de 106.000. Também, como no caso do Amazonas, o excesso de 145.000 para o Estado entre o esperado e real pode dever-se a erro de amostragem. Como no caso do Amazonas, não há evidência nenhuma que indique imigrações massivas de população para o Estado; certamente não há imigração massiva às áreas rurais.
No caso do Estado do Amazonas, a implantação da Zona Franca tem trazido como conseqüência uma migração massiva da população das áreas rurais às áreas urbanas (mais especificamente Manaus) do Estado; Manaus tem assim atuado como um ímã que em termos gerais tem prejudicado o desenvolvimento rural do Estado.

Temos então, que não há, até o presente, evidência que apoie o postulado de Goodland \& Irwin (1975) de um milhão de imigrantes rurais; ao contrário, a população rural está sendo absorvida pelas cidades em maior ou menor grau.

\section{EDUCAÇÃO}

\section{ENSINO PRÉ-ESCOLAR (Alfabetização).}

Nesta categoria, estão sendo incluídas tơdas as crianças entre dois e seis anos de idade.

Em termos gerais, o ensino pré-primário pode ser considerado quase que inexistente na Amazônia; temos assim que em 1975, o Amazonas tinha 4.600 crianças matriculadas em pré-primário; o Pará aproximadamente 7.000 e Mato Grosso 5.600, sendo que $75 \%$ das Instituições que têm ensino pré-primário são particulares.

Há evidência que sugere que o pré-primário é de grande importância no processo educativo da criança, sendo que é a época de formação de hábitos de estudo e trabalho mais importante (Margaret Charlwood, com. pessoal). O INPA está atualmente realizando estudos sobre a importância da adaptação de crianças à escola com base nos trabalhos realizados na escolinha pré-primária deste Instituto.

\section{ENSINO DE 1\% GRAU}

O Ensino de $1^{\circ}$ grau deve ser uma das maiores preocupações do governo, no campo educacional. A situação do ensino do primeiro grau na Amazônia é certamente alarmante; porém, não há evidência que indique que esta situação tenha piorado nos últimos anos.

Inicialmente, pensou-se, que com as predições de Goodland \& Irwin (1975), em relação ao influxo de pessoal postulado por eles, a situação educativa teria sofrido bastante. 
A figura 2 indica a situação de ensino de 10 grau para o Estado do Amazonas, no ano de 1975. As percentagens referem-se ao número de crianças, entre 7 e 14 anos, matriculadas no $1^{\circ}$ grau.

Certamente, a situação rural não deixa de ser crítica, com quase a metade do Estado, tendo menos de $40 \%$ do pessoal da faixa etária dos 7-14 anos no $1^{\text {o }}$ grau. Porém, com exceção da micro-região de Solimões - Japurá, todas as micro-regiões aumentaram a percentagem de estudantes na faixa etária acima notada entle 1970 e 1975. Existe então uma ligeira melhora na situação do primeiro grau com relação à faixa etária que deve estar matriculada nele. A situação é similar para o Pará e Mato Grosso. Em termos gerais, a situação é quase idêntica para toda a Amazônia.

A Figura 3 indica as matrículas, em ensino de primeiro grau, de acordo com a idade $\mathrm{e}$ com a série para os Estados do Amazonas, Pará e Mato Grosso somados.

Como pode observar-se, na figura, a grande maioria dos indivíduos qquase $50 \%$ estão matriculados na $1^{a}$ série com um grande decréscimo entre esta e a segunda série; isto indica que a maior parte das desistências no ensino de $1^{0}$ grau ocorre entre a $1^{\mathrm{a}}$ e $2 .^{\mathrm{a}}$ séries. Também, pode observar-se que a idade com maior número de alunos (descontando os maiores de 14 anos) está entre os 9 e 10 anos.

Com base nestes dados, pode ver-se que as crianças estão entrando tarde na escola e em grande parte desistindo após um ou dois anos de estudos. As exceções a isto, são as grandes cidades tais como Manaus, Belém e Cuiabá, nas quais as percentagens de estudantes estão bem distribuídas nas 8 séries de ensino do $1^{10} \mathrm{grau}$.



Fig. 2 - Percentagem de população na faixa etária de 7 - 14 anos, matriculada em ensino de $1 . .^{\circ}$ grau, nas diversas micro-regiões do Estado do Amazonas no ano de 1975; Micro-regiōes: 1 - Alto Amazonas; 2 - Juruá; 3 - Purus; 4 - Madeira; 5 - Solimões - Japurá; 6 - Rio Negro; 7 - Médio Amazonas excluindo Manaus; 8 - Manaus. (Dados baseados no Anuário Estatístico do Amazonas, 1975]. 


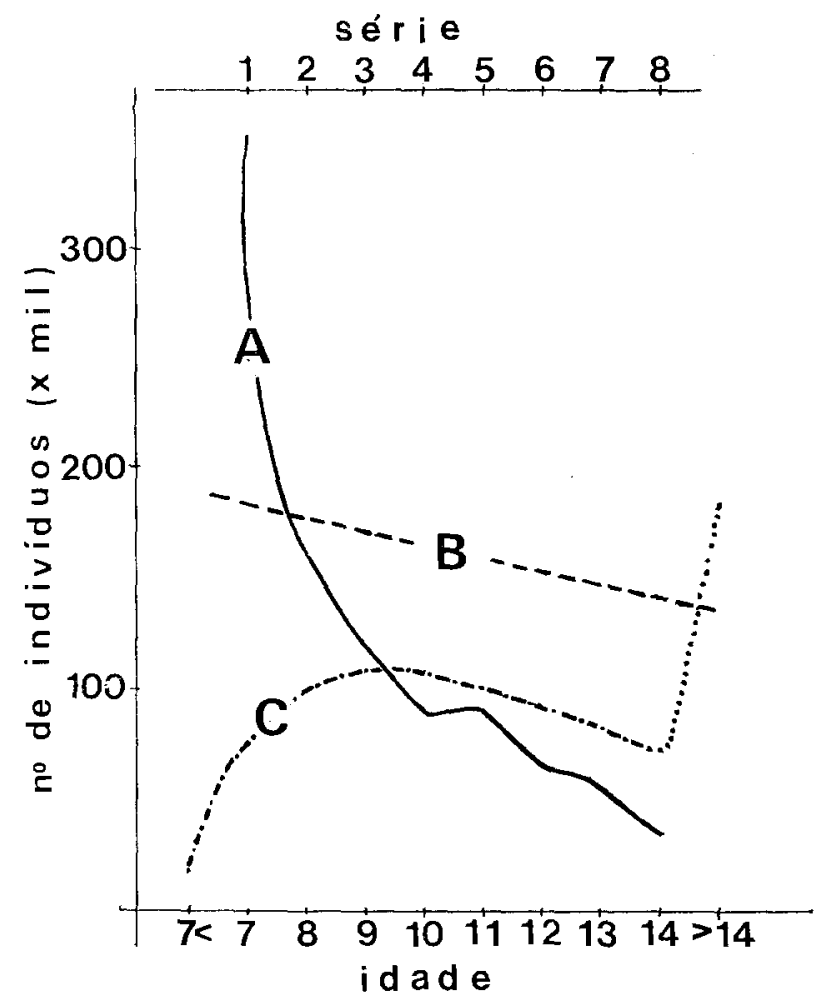

Fig. 3 - Matrícula em $1 .^{\circ}$ grau, segundo as séries e segundo as idades para os Estados do Amazonas, Pará e Mato Grosso. A - matrículas totais segundo a série; $B$ - n. ${ }^{\circ}$ total de indivíduos da população para as idades indicadas; C - número de indivíduos matriculados, segundo a idade.

A distribuição, em termos de matrículas entre as áreas rurais e urbanas, é semelhante para os três Estados aqui estudados. Os dados são apresentados na Figura 4.

Como pode observar-se na figura 4 , há mais matrículas nas zonas urbanas que nas


Fig. 4 - Matrículas de Ensino de 1.0 grau para o Amazonas, Pará e Mato Grosso. A - matrículas totais em percentagem rural e urbano; B - percentagem de conclusão do $1 .^{\circ}$ grau rural e urbano. áreas rurais o que não corresponde com as percentagens da população $(50 \%$ rural $\simeq 50 \%$ urbana). O número de conclusões nas áreas rurais é praticamente insignificante, correspondendo a $1 \%$ do total (no Pará variando entre $0,8 \%$ e $1,3 \%$; no Amazonas e Mato Grosso entre 0 e $1 \%$ ).

Tentou-se elucidar o fator ou fatores que podiam causar esta alarmante situação educacicnal, especialmente nas áreas rurais. Pensou-se, em primeiro lugar, na possibilidade de haver um número excessivo de alunos por professor. Os dados foram surpreendentes. Em termos gerais, para a Amazônia como um todo há uma média de 22 a 28 alunos por professor sendo esta média um pouco maior nas cidades que nas áreas rurais. Este número não pode ser considerado excessivo e está dentro de bons padrões sob o ponto de vista educativo.

Pensou-se também na possibilidade de o número de aprovações ser muito baixo face a erros no ensino e a falta de motivação. Os dados mostraram que as aprovações estão perto de $75 \%$ do total de alunos, o que também está dentro dos níveis considerados aceitáveis.

Foi feito um levantamento das qualificações do corpo docente para determinar até que ponto isto podia influir no grande número de desistências.

A Figura 5 mostra a situação do corpo docente nos Estados do Pará e Mato Grosso.

Como pode observar-se, pouco mais de uma quarta parte dos docentes de $1^{\circ}$ grau ou ainda não completaram o mesmo ou só o completaram; aproximadamente $10 \%$ tem ou está completando o $2^{\circ}$ grau, pouco mais de $35 \%$ tem ou está completando formação normalista. e $26 \%$ está fazendo ou completou a universidade; do total, $61 \%$ dos docentes têm forma. ção pedagógica.

Certamente, não deixa de ser alarmante que uma quarta parte do ensino do primeiro grau esteja em mãos de pessoal que só tem primeiro grau. Porém, a situação não é tão grave quanto podia ser. Há um número razoável de pessoal com formação pedagógica e uma percentagem considerável de pessoal com formação universitárịa. Não temos dados à disposição quanto à distribuição dos docentes 




Fig. 5 - Corpo docente de $10^{\circ}$ grau segundo nível de educação. Em todos os casos, as fatias menores de cada categoria representam pessoal que ainda não concluiu o curso indicado. 1 - com primeiro grau; 2 com segundo grau; $\mathrm{N}$ - normalista; $\mathrm{U}$ - universitário. A borda ondulada indica pessoal com formação pedagógica (cfp).

por nível de formação, quanto às áreas rurais e urbanas; porém pode pensar-se, a priori, que o nivel de corpo docente das áreas urbanas é substancialmente melhor que or das áreas rurais.

É possivel que a grande diferença entre as conclusões de $1^{\circ}$ grau entre as áreas rurais e urbanas seja devida às diferenças de nível do corpo docente nestas duas áreas; porém serão necessários mais dados para determinar esta situação.

O material didático utilizado pode ter uma grande influência na motivação dos estudantes a continuarem na escola. Em 1976, o INPA publicou uma cartilha para alfabetização, a cartilha da Amazônia, elaborada por G. P. Witter, W. E. Kerr e O. J. M. Fonseca. Esta cartilha foi utilizada experimentalmente numa série de escolas e comparada com outras usadas correntemente. Os resultados (Witter e Ramos, 1978) indicaram que os alunos que utilizaram esta cartilha preparada especialmente para a região e com assuntos regionais tiveram desempenho significativamente me-
Ihor que aqueles que utilizaram outras cartilhas convencionais.

Temos assim que em parte, as desistências podem ser devidas à falta de preparação do pessoal docente e material didático inapropriado; porém, a vivência das equipes de trabalho dos grupos de pesquisas do INPA, nas áreas de nutrição, ciências médicas e educação indicam que há uma total desmotivação dos pais e grande falta de interesse em que as crianças freqüentem à escola. Outra das observações destes grupos de trabalho indicz que muitos casais têm grande número de crianças simplesmente para receber os salários-família referente às mesmas. Há assiini uma tendência a ter famílias grandes e ignorar totalmente a educação das mesmas.

Em resumo, pode dizer-se que a educação de $1^{\circ} \mathrm{grau}$, ainda que muito carente, tem melhorado algo entre 1950 e 1980 , sendo que está atingindo uma maior percentagem das crianças em idade escolar. O corpo docente deve e pode ser melhorado, especialmente nas áreas rurais. Deve ser desenvolvido maierial didático na região.

Talvez, o mais importante é motiver os pais a enviarem as crianças à escola e na idade certa. Uma possibilidade seria interromper o salário família de toda criança aos 6 ou 7 anos e substituí-lo por um salário-educação que só seria recebido pelos pais mediante demonstração de que à criança está freqüentando normalmente à escola.

\section{ENSINO DE 2० GRAU}

Na Amazônia, o ensino de $2^{\circ}$ grau está praticamente limitado às áreas urbanas. $\mathrm{Na}$ Figura 6, pode observar-se a situação de matrículas para o $2^{\circ}$ grau em 1975, quando ao sexo e áreas rural e urbana.

Do total de matrículas de $2^{\circ}$ grau, só $1 \%$, ou menos, é rural e o resto urbana (Fig. $6 \mathrm{~A}$ ). Isto reforça a idéia de que as cidades estão atuando como polos de atração, em detrimento das áreas rurais. Atualmente, a Universidade do Amazonas tem montado 6 Campi Avançados no interior do Estado num esforço para começar um processo de descentralização dos núcleos de ensino superior. O Projeto Rondon 
e outros semelhantes devem ser encorajados a formar Campi Avançados para treinamento de $2^{\circ}$ grau, normalista e carreiras de nível técnico.

Da mesma forma, não adianta montar uma estrutura rural de $2^{\circ}$ grau sem ao mesmo tempo garantir um ensino de $1^{\circ}$ grau que leve a uma percentagem significativa de conclusões. Tem que ser um projeto acoplado conjuntamente entre os ensinos de $1 .^{\circ}$ e $2 .^{\circ}$ grau.

$\mathrm{Na}$ Fig. $6 \mathrm{~B}$, pode observar-se a grande percentagem de mulheres matriculadas no $2^{\circ}$ grau em relação a homens, o que reflete certamente a necessidade de os homens começarem a trabalhar mais cedo para sua manutenção. Por enquanto, não há solução fácil para esta situação, sendo que requer uma melhora geral das condições econômicas da população, que permita à população masculina começar a trabalhar em idades maiores do que as atuais.
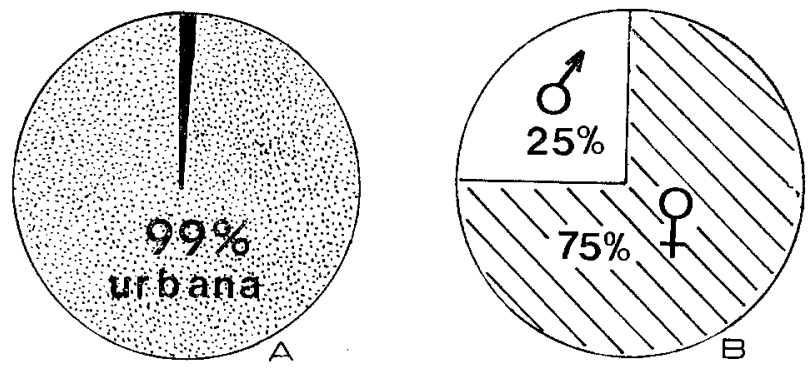

Fig. 6 - Ensino de 2.0 grau. A - por área rural ou urbana; B - por sexo.

\section{ENSINO SUPERIOR}

Nos últimos dez anos, todas as Universidades da Amazônia têm recebido grande apoio por parte dos governos federal e estadual. Em relação ao resto do país, o número de estudantes é baixo, porém está aumentando cada ano.

Não podemos esperar que a situação do ensino superior da Amazônia melhore repentinamente, já que requer a formação de corpos docentes idôneos, disponibilidade de candidatos (o que depende do ensino de $2^{\circ}$ grau) e montagem de facilidades físicas e equipamentos que são onerosos.
Porém, a ênfase dada à educação superior, nos últimos anos, já está começando a ter conseqüências favoráveis na Amazônia.

Ao mesmo tempo, tem que ser enfatizado o fato de a Amazônia representar territorialmente mais da metade do país com condições e problemática bem diferente das do resto do Brasil, e de que esta região é uma das menos conhecidas e pesquisadas no mundo, o que eventualmente vai requerer um grande número de pessoal qualificado, em todos os níveis e em disciplinas também variadas.

\section{PÓS-GRADUAÇÃO}

Um dos grandes problemas enfrentados no desenvolvimento da Amazônia é a falta de informação de como deve ser alcançado sem degradá-la. Embora a Amazônia ocupe mais de $50 \%$ do território nacional, possui menos de $0,5 \%$ do pessoal técnico e científico qualificado do país. As Universidades da região, assim como as Instituições de pesquisa da mesma, têm uma grande dificuldade em recrutar pessoal qualificado para trabalhar na Amazônia.

Atualmente, existem 8 cursos de Pós-Graduação na Amazônia com 180 estudantes matriculados, em contraste com mais de 850 cursos no resto do Brasil totalizando aproximadamente 33.000 estudantes (Della Senta, 1977). ou seja $0,5 \%$ dos alunos de Pós-Graduação do país representam a metade da área territorial do mesmo e $6 \%$ da população.

Nos últimos dois anos (1978-79), vem-se discutindo a excessiva proliferação da PósGraduação no Brasil (ex. Schwartzman, 1979) sugerindo-se uma concentração de recursos, por eliminação de Cursos. Argumenta-se (Schwartzman, 1979) que a Pós-Graduação è uma medida de excelência que não pode ser democraticamente distribuída por todo o território nacional!

Desafortunadamente, os mecanismos burocráticos de determinação de excelência estão distribuídos em dois ou três Estados que determinam os padrões para o país. Ao mesmo tempo, é notória a relutância do pessoal destes mesmos Estados em aceitar migrar para as áreas em desenvolvimento. Isto, a longo ou curto prazo, vai produzir um superávit 
de mestres e doutores concentrados em uma pequena parte do país e um déficit crescente dos mesmos nas áreas em desenvolvimento. onde são mais necessários.

Com base no ocorrido nos Estados Unidos onde a Pós-Graduação virou moda entre os anos de 1960 e 1970 e onde atualmente são produzidos 20 a 25 mil doutores por ano, este superávit vai ocorrer mais cedo do que se pode pensar.

Se somarmos isto à relutância do pessoal a migrar para Amazônia e se a "concentração de recursos" da Pós-Graduação é feita onde já há excesso de cursos, vai existir um desbalanço ainda maior entre o nível técnico e científico da Amazônia e o resto do país.

Historicamente, tanto nos Estados Unidos como em outros países, a Pós-Graduação teve o excesso de proliferação, entre outras razões, porque confere um "status" às Instituições que possuem cursos, e naturalmente quanto mais cursos, maior "status". Esta certamente não é a razão de criação de Pós-Graduação nas Instituições que têm cursos na Amazônia; como já foi dito anteriormente, foram criados para produzir pessoal qualificado para trabaIhar na região, vista a relutância de pessoal qualificado emigrar para Amazônia. De fato. têm sido bem sucedidos. É possível atrair estudantes de qualquer parte do Brasil, treiná-los e conseguir que fiquem na região, sendo que durante 0 treinamento começam a interessarse mais e mais pelo desafio que representa trabalhar na Amazônia.

Concluindo, é válido postular um excesso de cursos para a maior parte do país, porém não existem nem suficientes cursos e recursos na Amazônia para enfrentar o desafio de desenvolvê-la.

\section{EDUCAÇÃO INDIRETA}

Nem toda educação deve ou pode ser dada em programas formais. Atualmente admite-se [ver outros trabalhos desta publicação] que um dos grandes problemas da região é a fiscalização inadequada e aplicação de leis já existentes. Não adianta querer encher a Amazônia de fiscais e guardas Florestais; uma adequada fiscalização só poderá ser feita atra- vés da educação e conscientização da população; isto é uma fiscalização por consenso popular e não por imposição.

Qualquer programa de desenvolvimento deverá prioritariamente preocupar-se com a educação da população dentro de padrões compatíveis com a mesma. Em primeiro lugar, os resultados das pesquisas realizadas na Amazônia deverão ter ampla difusão dentro da mesma.Isto pode ser feito através do rádio, televisão e publicações populares de ampla distribuição.

Deve ressaltar-se também a importância de estabelecer museus, parques e zoológicos disponíveis a todos.

Devemos lembrar que a Amazônia é herança de seu povo e não podemos montar um excelente sistema de reservas, parques nacionais etc. sem ao mesmo tempo dar acesso ao povo a áreas de lazer e aprendizagem consideráveis. Em uma primeira etapa, deverá pensar-se em grandes áreas verdes nas cidades de fácil acesso e que ofereçam diversões educativas.

\section{CONCLUSÕES GERAIS}

Ainda se não há evidência de uma imigração massiva como postulado por Goodland \& Irwin (1975), tem havido uma migração considerável das áreas rurais às áreas urbanas especialmente no Estado do Amażonas. A população não tem aumentado além do crescimento esperado; tem havido porém uma redistribuição da mesma em detrimento das áreas rurais.

Para compensar esta tendência, será necessário melhorar consideravelmente as condições de vida e as opções de trabalho nas áreas rurais o que poderia ser feito com núcleos de colonização bem estruturados.

No campo educacional, tem havido um ligeiro progresso nos últimos 10 anos; porém o ensino primário continua sendo crítico, especialmente nas áreas rurais.

Além das soluções tradicionais, tais quais, melhor e maior corpo docente, mais escolas etc., a obrigatoriedade legal da educação primária tem que ser aplicada. Os pais têm que ser forçados e incentivados a enviar as crian- 
ças à escola desde cedo; um sistema pré-primário universal deve ser implantado e as crianças obrigadas a freqũentarem ao mesmo. Isto pode ser feito através de incentivos fiscals aos pais com crianças na escơla (salário-educacional). Em resumo, as crianças deverāo entrar na escola aos seis a sete anos e não, como atualmente, entre nove e dez.

A educação secundária deverá ser extendida às áreas rurais com ajuda de programas tais como o projeto Rondon, Campi Universitários Avançados e escolas normais.

A Graduaçãơ e Pós-Graduação deverão receber estímulos consideráveis por parte dos governos estaduais e federal, sendo, que são a base do desenvolvimento regional.

\section{BIBLIOGRAFIA}

Della Senta, I.M.C.

1977 - Situação atual da Pós-Graduação Brasill-77. Brasilia, MEC. DAU. CAPES.

GoOdland, R. \& IRWIN, $H$.

1975 - A Selva Amazônica: Do Inferno Verde ao
Deserto Vermelho? trad. de Regina Jun-
queira, revisão e notas de Mario G. Ferri.
São Paulo, Ed. Itatiaia, Ed. da Univ. de São Paulo.

Instrtuto do Desenvolvimento Econômico do Pará 1977 - Anuário Estatístico do Pará. 1(1) : 1-417.

Rebelo, D.C.

1973 - Transamazônica: Integração em Marcha. Ministério do Transporte, Rio de Janeiro. 243 p.

SCHWARTZMAN, S.

1979 - Que fazer com a Pós-Graduação? Debate, set 1979. Folheto publicado pela CAPES. p. 1-3

Secretaria de Planejamento e Coordenação Gral do Estado de Mato Grosso

$$
1975 \text { - Anuário Estatístico de Mato Grosso. }
$$
$7: 1-620$.

Secretaria de Planejamento do Estado do Amazonas 1975 - Anurário Estatístico do Amazonas. 6 : 1-303.

WitTer, G.P. \& Ramos, M.A.A.

1978 - "Cartilha da Amazônia": Produção e teste de material de aprendizagem. Ciência e Cultura, 30(6) : 677-685.

Witter, G.P.; Kerr, W.E. \& Fonseca, O.J.M.

1977 - Cartilha da Amazônia. Imprensa Oficial do Estado do Amazonas, Manaus. 